\title{
CC-type glutaredoxins mediate plant response and signaling under nitrate starvation in Arabidopsis
}

\author{
Ji-Yul Jung ${ }^{1 *}$ D, Ji Hoon Ahn ${ }^{1}$ and Daniel P. Schachtman ${ }^{2^{*}}$
}

\begin{abstract}
Background: Nitrogen is an essential nutrient in plants. Despite the importance of nitrogen for plant growth and agricultural productivity, signal transduction pathways in response to nitrate starvation have not been fully elucidated in plants.

Results: Gene expression analysis and ectopic expression were used to discover that many CC-type glutaredoxins $\left(R O X Y_{S}\right)$ are differentially expressed in response to nitrate deprivation. A gain-of-function approach showed that ROXYs may play a role in nutrient sensing through the regulation of chlorophyll content, root hair growth, and transcription of nitrate-related genes such as NRT2.1 under low or high nitrate conditions. Reactive oxygen species (ROS) were produced in plant roots under nitrate starvation and $\mathrm{H}_{2} \mathrm{O}_{2}$ treatment differentially regulated the expression of the ROXYS, suggesting the involvement of ROS in signaling pathways under nitrate deficiency.

Conclusion: This work adds to what is known about nitrogen sensing and signaling through the findings that the ROXYs and ROS are likely to be involved in the nitrate deprivation signaling pathway.
\end{abstract}

Keywords: Glutaredoxin, ROXY, Nitrate, Starvation, ROS, Signaling

\section{Hightlight}

CC-type glutaredoxins play roles in plant response and signaling under nitrate starvation conditions in Arabidopsis possibly acting downstream of reactive oxygen species.

\section{Background}

Plants require nutrients to complete their life cycle. Among them, nitrogen is required in greater abundance and is essential for plant growth. Plant roots preferentially take up nitrate and ammonium from the soil although they have the capacity to absorb organic $\mathrm{N}$ sources, such as amino acids, in soils that contain high concentrations of organic matter [1, 2]. In aerobic soil conditions, ammonium and amino acids are poorly available and nitrate is relatively abundant in the anionic form which is readily dissolved in soil water. Therefore, plants tend to use nitrate as the main source of

\footnotetext{
* Correspondence: vinejung@gmail.com; daniel.schachtman@unl.edu ${ }^{1}$ Department of Life Sciences, Korea University, Seoul 02841, South Korea ${ }^{2}$ Department of Agronomy and Horticulture, Center for Biotechnology, University of Nebraska Lincoln, Lincoln, NE 68588, USA
}

inorganic nitrogen [3-5]. Since nitrogen availability in plants can be affected by various environmental conditions, including soil $\mathrm{pH}$, soil type, precipitation, and temperature $[4,6]$, plants frequently experience nitrogen deficiency, which can greatly reduce the yield of plants. Therefore, studying plant responses to nitrogen deficiency is of significant agricultural importance.

Although certain aspects of how plants respond to nitrogen deprivation at physiological and transcriptional levels are known, the details of the signaling pathways in response to low or high nitrogen are not well characterized [7-12]. Nitrogen starvation in plants induces both physiological changes of root structures and transcriptional changes of nitrogen-related genes such as AMT1 ammonium transporters and NRT2 nitrate transporters including NRT2.1, a main contributor in nitrate uptake during nitrogen starvation $[12,13]$. Many factors are reported to be involved in low nitrogen-induced plant responses. These include transcription factors (LATERAL ORGAN BOUNDARY DOMAIN (LBD) 37/38/39 and NIN-LIKE PROTEIN (NLP) 7), components of peptide signaling (C-TERMINALLY ENCODED PEPTIDE

(c) The Author(s). 2018 Open Access This article is distributed under the terms of the Creative Commons Attribution 4.0 International License (http://creativecommons.org/licenses/by/4.0/), which permits unrestricted use, distribution, and 
(CEP), CEP RECEPTOR1/2 (CEPR1/2), CLAVATA3/ ESR-RELATED (CLE) 1/3/4/7, and CLAVATA1 (CLV1)), microRNAs (miR169), and plant hormones (cytokinin and auxin) [12, 14-20]. Calcium signaling may be a component in low nitrogen signaling as CALCINEURIN B-LIKE PROTEIN 7 (CBL7) is involved in the regulation of root growth under nitrate limitation in Arabidopsis [21]. Reactive oxygen species (ROS) are also implicated in the low nitrate signaling because $\mathrm{H}_{2} \mathrm{O}_{2}$ concentrations in plant roots increased in response to nitrogen starvation $[22,23]$. It is known that ROS as a signaling molecule mediates signal transduction in plants under the deprivation of some nutrients such as potassium [24], phosphate [25], and boron [26]. And NADPH oxidases are mainly responsible for low nutrient-induced ROS production based on chemical inhibitor and genetic studies $[22,27,28]$.

Glutaredoxins (GRXs) are small ubiquitous proteins that are involved in disulphide bridge or protein-glutathione reduction in plant cells [29-36]. There are 31 GRX genes in Arabidopsis that can be classified into three distinct subgroups based on the amino acid sequences at their active sites: the CPYC, CGFS, and CC-type GRX classes [32, 35]. Out of the 31 GRXs in Arabidopsis, 21 GRXs belong to the CC-type class, which is specific for land plants, while the other two GRX classes, CPYC and CGFS, are common to eukaryotes and prokaryotes [31, 37-39]. Although the roles of GRXs have been associated mainly with oxidative stress [40-52], there is growing evidence that GRXs, especially CC-type GRXs, also play important roles in cell signaling and development [30, 33, 34, 53-60]. For example, three CC-type GRXs, ROXY1, ROXY2, and ROXY4, which interact with TGA transcription factors in the nucleus, are required for flower development [36, 54, 55, 61-64] and another CC-type GRX gene, ROXY19, has been demonstrated to act as a repressor in the detoxification pathways [65] and pathogen responses through salicylic acid (SA)/jasmonic acid (JA) signaling [36, 66, 67]. ROXY19 was also shown to act as an adapter protein for the assembly of transcriptional repressor complexes on TGA-regulated target promoters [68]. Recently, it was shown that ROXY11-13 and ROXY15 are involved in nitrate-induced primary root growth inhibition $[57,69]$.

Previous microarray studies indicated that many ROXYs are differentially expressed under abiotic stresses, suggesting the involvement of ROXYS in abiotic stress [70]. However, not much is known about the gene expression of ROXYs under low nutrient stress and the functional consequences of the changes in their expression. In this study, we quantified changes in the gene expression of ROXYS under low nutrient conditions by removing nitrogen from media. We found that a number of ROXYs are differentially regulated in response to nitrate starvation. Based on the phenotypes of overexpression lines of two ROXYs (ROXY9 and ROXY15), evidence is provided showing a role for CC-type GRXs in nitrate starvation signaling. ROS appears to be another component that regulates the differential expression of $R O X Y s$ under nitrate deprivation conditions. This study provides important new information that further elucidates additional novel components in the complex nitrate signaling pathway in plants.

\section{Results}

\section{Nitrate starvation differentially regulates the expression} of ROXYs

In Arabidopsis, there are 21 CC-type GRXs, which have been named ROXY1 to ROXY21 [47]. To determine the expression pattern of $R O X Y S$ under various reduced nutrient conditions, quantitative real time PCR (qRT-PCR) was used to measure the ROXYs mRNA level in the wild type Columbia- 0 seedlings grown on full nutrient medium $(+\mathrm{N})$ and no nitrate medium $(-\mathrm{N})$. As a nitrogen source in nutrient medium, we only used nitrate and not ammonium since ammonium is poorly available in actual soil conditions. Sixteen $R O X Y$ genes tested in this study showed altered transcriptional responses in plants under nitrate starvation. The expression of six ROXYs (ROXY6,8,9,1921) was significantly upregulated by nitrate deficiency (Fig. 1a), while the expression of 10 ROXYS (ROXY7,10-18) was downregulated (Fig. 1b). These data suggest that $R O X Y$ genes may be involved in signaling pathways under nitrate deficiency conditions in plants.

\section{Possible roles of ROXYs under nitrate-sufficient or -deficient conditions}

Nitrate deprivation was shown to differentially regulate the expression of ROXYs, suggesting that these genes may play an important role under the nitrate starvation conditions. To further investigate the possible functional roles of ROXYs in response to nitrate deficiency, an overexpression approach was chosen due to the large size of the gene family and a potential issue related with redundancy making it difficult to reveal phenotypes of knockout lines. Two independent transgenic Arabidopsis lines overexpressing ROXY9 or ROXY15 (Additional file 1) were used for their phenotypic analyses. The reason we chose these two ROXY genes is that they showed the opposite transcriptional regulation under nitrate starvation: ROXY9 is upregulated and ROXY15 is downregulated by nitrate deprivation (Fig. 1). Compared with the wild type plants grown in soils, leaf chlorophyll content was significantly lower in the two independent lines overexpressing ROXY9 and higher in the two independent lines overexpressing ROXY15 (Fig. 2a, b). Wild 


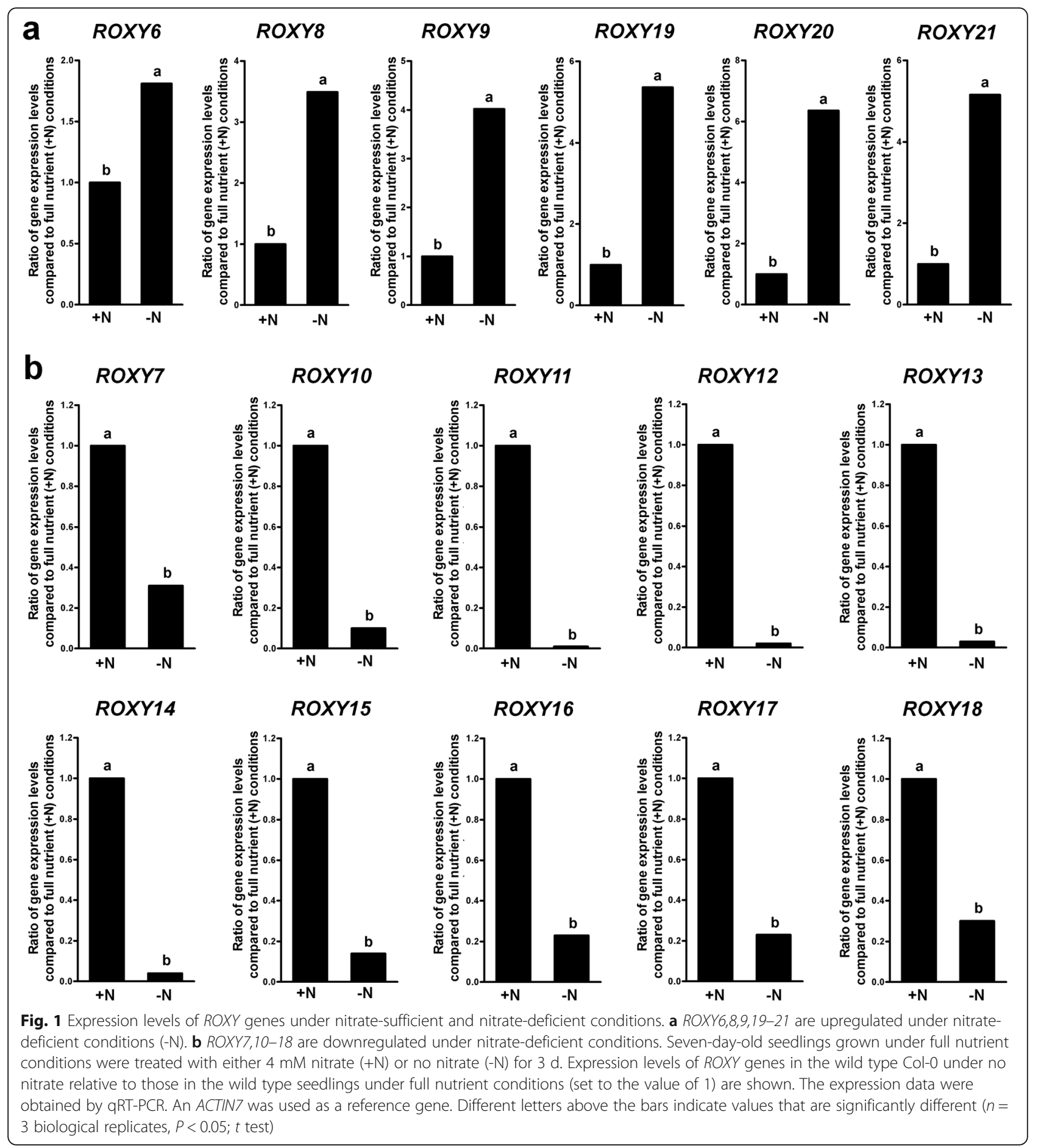

type plants grown under nitrate starvation conditions had lower chlorophyll contents when compared with those grown under nitrate-sufficient conditions (Fig. 2c). Also compared with the wild type seedlings grown on full nutrient medium, the length of root hairs was significantly longer in the two independent lines overexpressing ROXY9 and shorter in the two independent lines overexpressing ROXY15 (Fig. 3a, b). And nitrate deficiency in wild type seedlings promoted root hair elongation (Fig. 3c).

To determine whether ROXYs mediate the transcriptional regulation under nitrate starvation, qRT-PCR was used to measure the mRNA levels of nitrate-related genes that are involved in nitrogen uptake in the two 
a

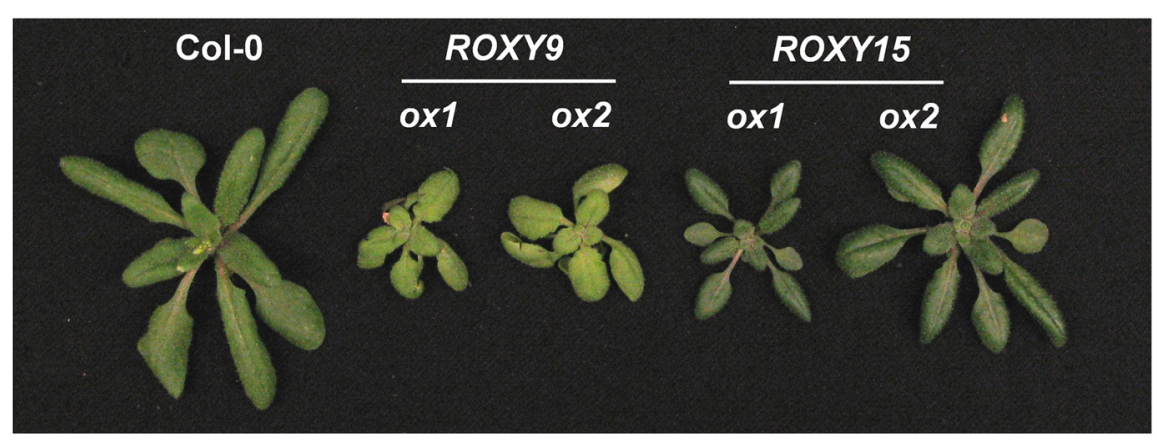

b

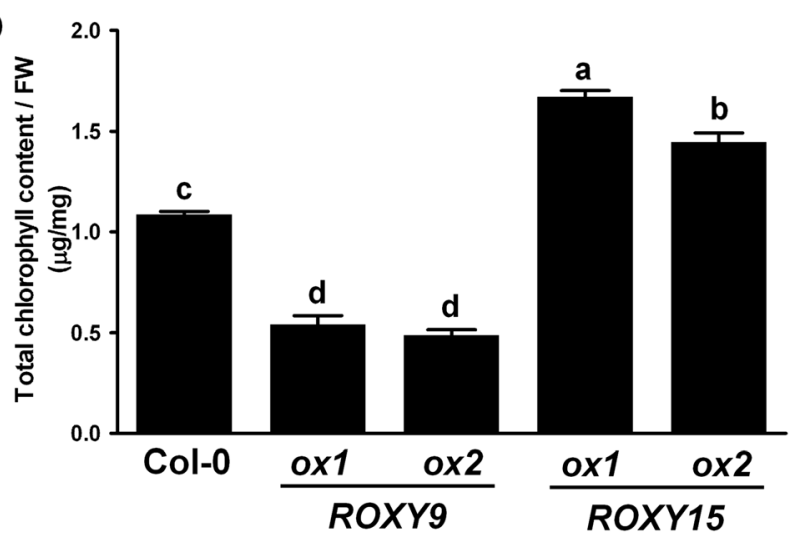

C

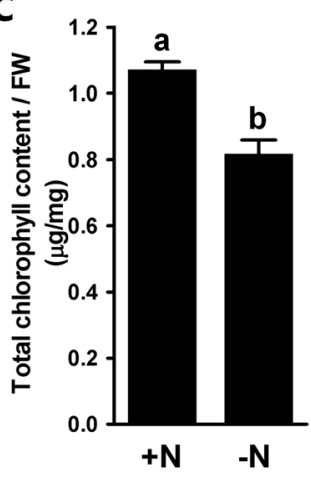

Fig. 2 Overexpression of ROXY9 reduces chlorophyll content while overexpression of ROXY15 increases chlorophyll content. Images of shoots of three-week-old plants grown in the soil. a Wild-type plants and two independent transgenic plants overexpressing ROXY9 or ROXY15 (ox) were grown for three weeks in the soil and their leaf chlorophyll contents were measured as described in the Method section. $\mathbf{b}$ Total chlorophyll content of plants shown in (a). Fully developed mature leaves were used for the measurement of chlorophyll content. The total chlorophyll content was expressed as micrograms per milligram leaf fresh weight. Values are mean \pm SE from two leaves per plant ( $n=10$ plants). Results from one of two independent experiments are shown. c Total chlorophyll content of wild type Col-0 plants deprived of nitrate. Ten-day-old seedlings grown on complete nutrient media were treated with either $4 \mathrm{mM}$ nitrate $(+\mathrm{N})$ or no nitrate $(-\mathrm{N})$ for 4 days. Values are mean \pm SE from 5 shoots per replicate ( $n=5$ replicates). Results from one of two independent experiments are shown. Different letters above the bars indicate values that are significantly different $(P<0.05 ; t$ test $)$

independent lines overexpressing ROXY9 or ROXY15. Compared with the wild type seedlings grown on full nutrient medium, the expression of NRT2.1 was significantly higher in the two independent lines overexpressing ROXY9 and lower in the two independent lines overexpressing ROXY15 (Fig. 4a). The change in NRT2.1 transcriptional levels in wild type plants under nitrate deficiency was also investigated. The expression of NRT2.1 was upregulated when plants placed on medium that did not contain nitrate for $6 \mathrm{~h}$ and $12 \mathrm{~h}$ (Fig. 4b).

\section{Nitrate starvation induces ROS production at root hair differentiation zone and ROS treatment differentially regulates the expression of ROXYS}

Nitrate starvation has been shown to induce about a 2-fold increase of ROS in Arabidopsis roots [22] implicating ROS as a component of the response to low concentrations of nitrate. To confirm the previous findings, ROS was measured in wild type seedlings under nitrate-sufficient conditions and nitrate-deficient conditions by staining roots with 5-(and 6-) carboxy-2',7'-difluorodihydrofluorescein diacetate (DFFDA) that detects ROS [24]. Under nitrate-sufficient conditions, small amounts of ROS were detected mainly in the root hair differentiation zone (RHDZ) of the roots (Fig. 5a, b). Under nitrate-deficient conditions, ROS significantly increased in the RHDZ of the roots, showing that the results are consistent with previous findings [22]. To determine whether or not ROS regulates the expression of $R O X Y$ genes, we treated wild type seedlings with $\mathrm{H}_{2} \mathrm{O}_{2}$ and investigated the expression pattern of ROXYS in response to ROS. ROS treatment significantly increased the expression of ROXY9,19,21 (Fig. 5c), whose expression was also enhanced by nitrate deprivation (Fig. 1a). The ROS treatment significantly reduced the expression of ROXY10 through ROXY15 and ROXY17 (Fig. 5d), whose expression was reduced by nitrate deprivation (Fig. 1b). These data suggest that ROS may act upstream of the expression of the $R O X Y$ genes in nitrate deprivation signaling. 

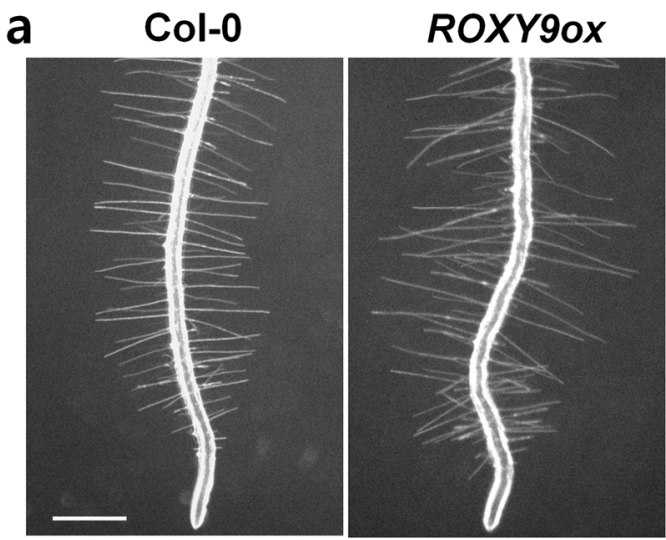

\section{ROXY150X}
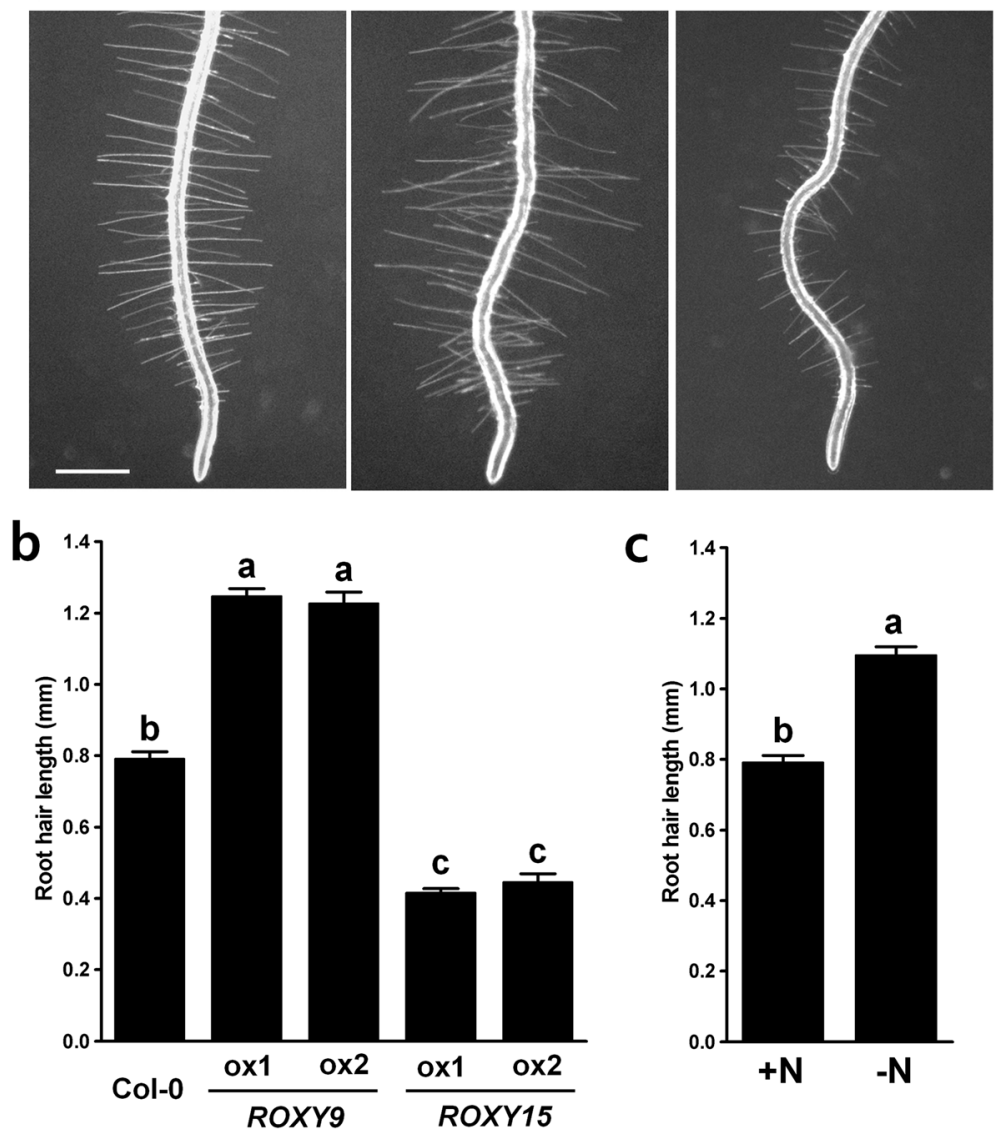

Fig. 3 Overexpression of ROXY9 stimulates root hair elongation while overexpression of ROXY15 inhibits root hair elongation. (a, b) Light microscopy images showing root hairs of wild-type Col-0 seedlings and two independent transgenic seedlings overexpressing ROXY9 or ROXY15 (ox). Roots from four-day-old seedlings grown on nitrate-sufficient medium were used for the measurement of the root hair length. Bar $=0.5 \mathrm{~mm}$. b Quantified data showing the root hair length of wild-type Col-0 seedlings and two independent transgenic seedlings overexpressing ROXY9 or ROXY15 ( $n=10$ seedlings, means \pm SE). c Root hair length of wild type Col-0 seedlings grown under nitrate-sufficient ( $+\mathrm{N})$ and nitrate-deficient $(-\mathrm{N})$ conditions ( $n=10$ seedlings, means \pm SE). Four-day-old roots treated with either $4 \mathrm{mM}$ nitrate or no nitrate for $24 \mathrm{~h}$ were used for the measurement of root hair length. Results from one of two independent experiments are shown here. Different letters above the bars indicate values that are significantly different $(P<0.05 ; t$ test $)$

\section{Discussion}

Despite the importance of nitrogen for plant growth and agricultural productivity, signal transduction pathways in response to changes in external and internal nitrogen concentrations in plants have not been fully elucidated. In this study, we analyzed the gene expression patterns of 16 out of $21 R O X Y$ genes under nitrate deprivation conditions and found that all $16 R O X Y$ genes are differentially regulated under nitrate starvation. A gain-of-function approach suggested a role for the ROXYs in the regulation of chlorophyll content, root hair growth, and transcription of NRT2.1 under nitrate starvation conditions. We also showed that ROS production increases under nitrate deficiency and that ROS treatment also differentially regulates the expression of the ROXY genes. This work suggests possible roles of ROXYs and ROS in nitrate starvation signaling.
We showed that nitrate deprivation induces the differential regulation of $R O X Y$ genes: upregulation of 6 ROXYs (ROXY6,8,9,19-21) and downregulation of 10 ROXYS (ROXY7,10-18) (Fig. 1). Similar transcription pattern of some $R O X Y$ genes was found in a transcriptional profiling data set where $100 \mu \mathrm{M}$ of nitrate was used to deprive plants [71]. It was also shown that the expression of 7 ROXY genes (ROXY4,11-13,15-17) was induced by the addition of nitrate [57] highlighting the importance of this gene family in nitrate response. Our data showing downregulation of the 6 ROXYS (ROXY1113,15-17) under nitrate deprivation differ from previous findings [57] in that we studied response to nitrate deficiency rather than induction by high nitrate. In nitrate response for which nitrate is added to plants grown on media that used ammonium as a sole nitrogen source, the nitrate transporter NRT1.1 (CHL1/NPF6.3) turned 

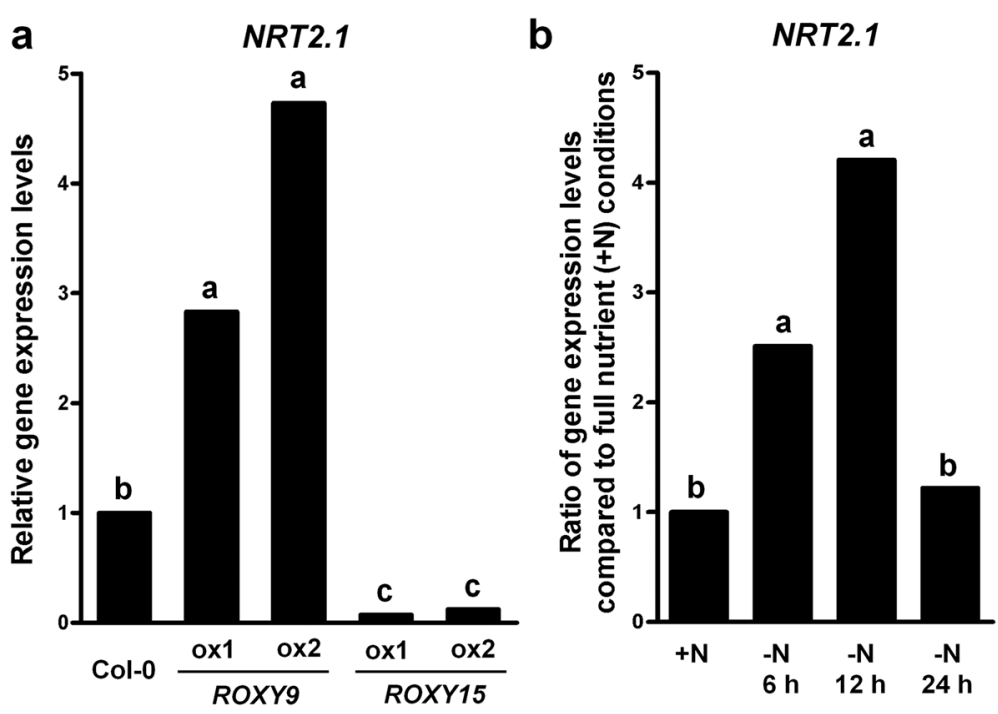

Fig. 4 Overexpression of ROXY9 causes the upregulation of the expression of NRT2.1 while overexpression of ROXY15 leads to the downregulation of the expression of NRT2.1. a Expression levels of NRT2.1 in two independent transgenic seedlings overexpressing ROXY9 or ROXY15 (ox) relative to those in the wild type Col-0 seedlings (set to a value of 1). Seven-day-old seedlings grown on complete nutrient medium were used and the expression data were obtained by qRT-PCR. An ACTIN7 was used as a reference gene. Different letters above the bars indicate values that are statistically different ( $n=3$ biological replicates, $P<0.05 ; t$ test). $\mathbf{b}$ Expression levels of NRT2.1 in the wild type Col-0 seedlings under nitrate-deficient conditions. Expression levels of NRT2.1 in Col-0 seedlings under nitrate-deficient conditions relative to those in Col-0 seedlings under nitrate-sufficient conditions (set to a value of 1). Six-day-old seedlings were grown on complete nutrient media and transferred to media with either $4 \mathrm{mM}$ nitrate $(+\mathrm{N})$ or no nitrate $(-\mathrm{N})$, and further grown for 6,12 , and $24 \mathrm{~h}$. Then, all seedlings were harvested at the end of the light period (zeitgeber time 16). An ACTIN7 was used as a reference gene. Different letters above the bars indicate values that are statistically different $(n=3$ biological replicates, $P<0.05 ; t$ test)

out to be an important player which acts as a nitrate sensor that regulates the response to nitrate addition $[72,73]$. We have some evidence that the differential regulation of ROXYS under nitrate starvation is altered in the mutants of NRT1.1 only in the presence of ammonium (data not shown). These data indicate that NRT1.1 may also play a role in nitrogen starvation signaling and that nitrogen starvation response and response to nitrate addition may share some signaling components such as ROXYs and NRT1.1 under certain circumstances (e.g. in the presence of ammonium).

It appears that ROXYs are involved not only in plant responses to nitrate deprivation but also in plant responses to other low nutrients such as potassium, phosphorus, sulfur, and iron. We found that $R O X Y 7$ and $R O X Y 16$ are upregulated under low phosphate conditions, while $R O X Y 18$ is upregulated under low potassium conditions (Additional file 2). Genevestigator microarray database also showed that ROXY10 is upregulated by iron deprivation and ROXY4 and ROXY12 are downregulated by sulfur deprivation (data not shown). These data indicate that ROXYs may act as downstream regulators in plant signaling pathways triggered in response to nutrient deficiencies.

To understand the possible roles of ROXYs under nitrate-sufficient and nitrate-deficient conditions, we analyzed the phenotypes of transgenic lines overexpressing $R O X Y 9$, which is normally upregulated, and $R O X Y 15$, which is normally downregulated, under nitrate starvation conditions. We showed that transgenic lines overexpressing $R O X Y 9$ had lower chlorophyll content compared to wild type plants while transgenic lines overexpressing ROXY15 had higher chlorophyll content and that nitrate deficiency led to the decrease of chlorophyll content (Fig. 2). Consistent with our finding, it is known that nitrogen deficiency represses chlorophyll synthesis-related genes and the chlorophyll content is also reduced during low nitrogen conditions [71, 74-76]. These findings suggest that ROXY9 or its paralogs might play a role in chlorophyll synthesis as a negative regulator under nitrate-deficient conditions while ROXY15 or its paralogs might play a role in chlorophyll synthesis as a positive regulator under nitrate-sufficient conditions. The overexpression of OsGRX6, a rice CC-type GRX that shows a high similarity to AtROXY18, increased chlorophyll content and nitrogen content [56] supporting our finding that ROXYs may be involved in chlorophyll synthesis, which may depend on external nitrate status in plants.

We showed that transgenic lines overexpressing ROXY9 had longer root hairs compared to wild type plants, while transgenic lines overexpressing ROXY15 


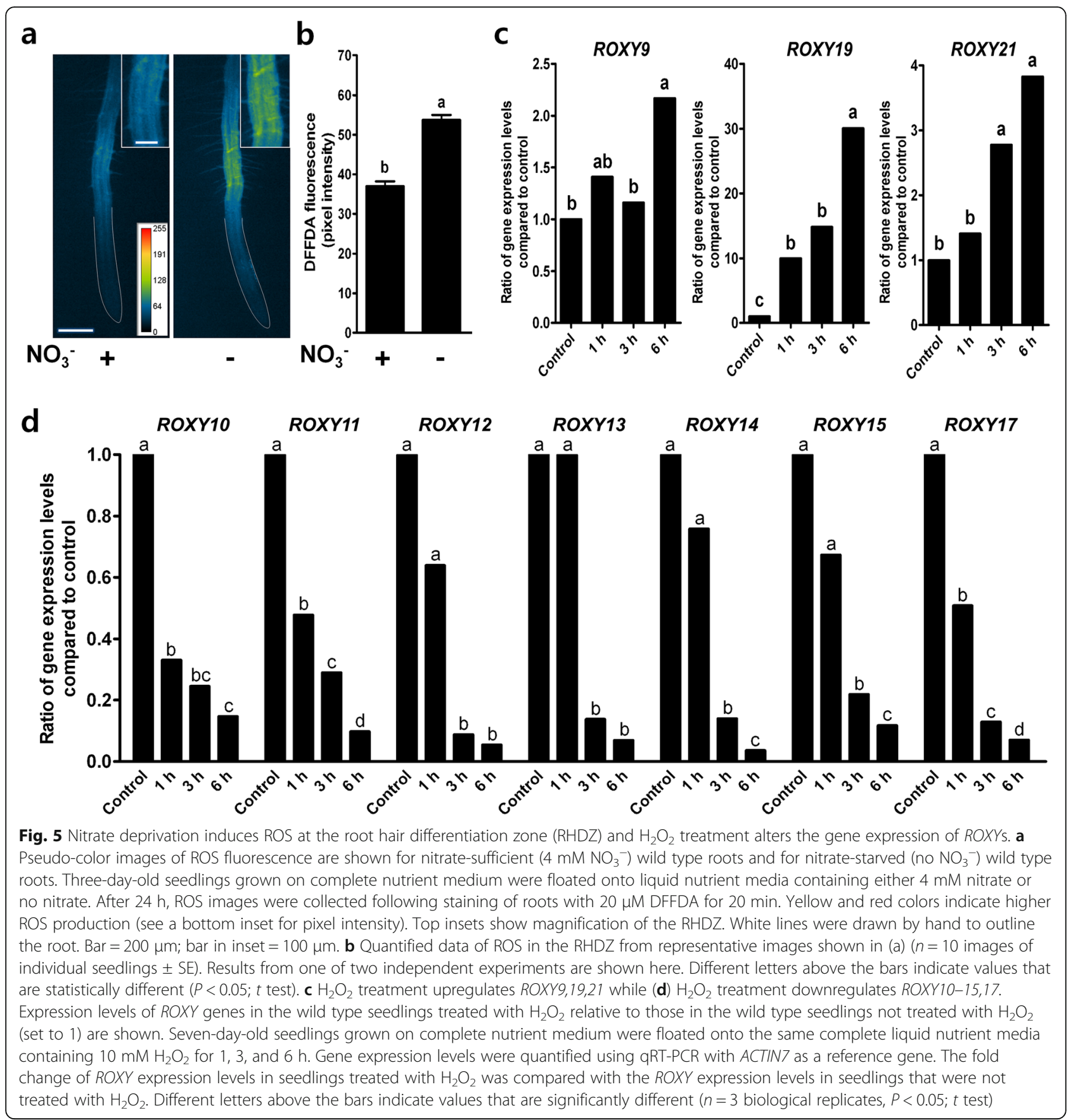

had shorter root hairs (Fig. 3a and b). Previously it was reported that nitrogen deprivation stimulates root hair elongation in Arabidopsis roots [77, 78]. Also, we found that roots deprived of nitrate for $1 \mathrm{~d}$ had longer root hairs compared to roots under nitrate-sufficient conditions (Fig. 3c) confirming the previous report. Based on these data, it is possible that ROXY9 or its paralogs might stimulate root hair elongation under nitrate-deficient conditions, while ROXY15 or its paralogs might inhibit root hair elongation under nitrate-sufficient conditions. These results also support a role for ROXY9 under nitrate-deficient conditions and ROXY15 under nitrate-sufficient conditions.

We also showed that the expression of NRT2.1, a major contributor in nitrogen uptake under nitrogen limitation [12], is differentially regulated in transgenic ROXY9- or ROXY15- overexpressor lines. The expression of NRT2.1 was significantly upregulated in transgenic lines overexpressing ROXY9 under full nutrient conditions but downregulated in transgenic lines overexpressing ROXY15 (Fig. 4a). And nitrate deficiency in 
plants caused the upregulation of NRT2.1 (Fig. 4b). Consistent with our data, it was shown that expression of NRT2.1 is downregulated under nitrogen-sufficient conditions and upregulated by nitrogen starvation [12, 79-82]. Based on these findings, it is possible to speculate that ROXY9 or its paralogs might stimulate NRT2.1 expression under nitrate-deficient conditions while ROXY15 or its paralogs might repress NRT2.1 expression under nitrate-sufficient conditions which is consistent with our gene expression analyses. Likewise, the gain-of-function studies of $R O X Y$ genes provided some evidence about the possible roles of the $R O X Y$ genes in the regulation of gene expression and physiological change of plants in response to nitrate deficiency. As well as the gain-of-function studies, we also tried to use a loss-of-function approach by creating plants carrying RNAi constructs that specifically target one or multiple ROXY gene(s). Although we succeeded in making transgenic lines where a ROXY9 was silenced or both ROXY8 and ROXY9 were silenced, we did not find any phenotype in these RNAi lines (data not shown) probably due to a high redundancy of the ROXY gene family in the Arabidopsis genome. Recently it was shown that silencing ROXY15 and its homologs, which are nitrate-inducible, caused a long primary root phenotype in nitrate-sufficient conditions, indicating that ROXY15 and its homologs are involved in nitrate-mediated primary root growth [57]. Taken together, our work and previous studies provide new important clues as to the possible roles of ROXYs in plant signaling pathways under deprived or high nitrate conditions.

We showed in this work that nitrate starvation increases ROS production using DFFDA, which confirms our previous work [22]. Our additional new experiments show that $\mathrm{H}_{2} \mathrm{O}_{2}$ treatment downregulates $R O X Y 10-15$ and ROXY17 and upregulates ROXY9,19,21 (Fig. 5). Moreover, we also found that ROXY16 and ROXY18, which are induced by phosphate- and potassium deficiency, respectively, are also upregulated by ROS treatment while low phosphate-inducible ROXY7 is not altered by ROS treatment (Additional file 2). These data indicate that ROS may act upstream of some ROXYs in nitrate starvation signaling as it has been shown for responses to low potassium [24]. However, we cannot exclude the possibility that there might be positive feedback regulation so that ROS-induced ROXYs may further stimulate ROS production. Respiratory Burst Oxidase Homolog C (RBOHC) NADPH oxidase RHD2 was shown to be responsible for the low potassium-induced ROS production and the expression of $H A K 5$, a low potassium-inducible potassium transporter $[22,24]$. These results with ROXY and our previous results [22] suggest that RHD2 is not sufficient alone for nitrate signaling since the differential regulation of ROXY genes in $r h d 2$ in response to nitrate deprivation was the same as that of ROXY genes in Col-0 wild type (Data not shown) and our previous results also showed that ROS production was attenuated, but not abolished in the rhd2 mutant.

An open, related question is how ROXYs regulate their downstream targets. Our data using transgenic ROXY overexpressors reveal the complete opposite roles of ROXYs in plant phenotype and transcriptional regulation despite their high homology. GRXs are involved in disulphide bridge reduction or protein S-glutathionylation, a posttranslational modification, in plant cells $[29,30]$. It was suggested that GRXs regulate many targets that are involved in various cellular processes including oxidative stress responses, nitrogen, sulfur, and carbon metabolisms, translation, and protein folding via the reduction of disulphide bridge [83]. GRXs-mediated protein glutathionylation may also be an important mechanism to regulate protein activities. In animals, GRXs were also shown to glutathionylate transcription factors leading to the alteration of their DNA binding activity [84]. In plants, CC-type GRXs ROXY1/2 and ROXY19 were reported to interact with TGA transcription factors and suggested to act as regulators of TGA transcription activity probably by glutathionylation that affects flower development and the SA/JA signaling, respectively $[61,62,66]$. A recent report suggested a possible role of ROXYs as adapter proteins for the assembly of transcriptional repressor complexes on TGA-regulated target promoters [68]. In this context it was shown that in response to nitrate TGA1 and TGA4 transcription factors play important roles in the regulation of gene expression of NRT2.1 and NRT2.2 and modulation of primary root length and lateral root density [85]. Based on our finding that the gene expression levels of NRT2.1 were significantly altered in the ROXY9 and ROXY15 overexpression lines (Fig. 4), we hypothesize that the ROXYs that are differentially regulated under high and low nitrate conditions could regulate the gene expression of NRT2.1 probably either through ROXYs-mediated glutathionylation or disulphide bridge reduction of TGA1/4 or through acting as adaptor proteins, which may help recruit transcriptional complexes on TGA-regulated target promoters. Further studies will be necessary to test this hypothesis.

\section{Conclusion}

The data presented here provide evidence that both ROS and $R O X Y$ genes may play an important role in nitrate deprivation signaling. A model for the role of ROXYs in nitrate deprivation signal transduction pathway is summarized in Fig. 6. Our findings provide new and supportive data connecting known signaling components with nitrogen limitation-regulated plant responses (i.e. physiological changes and transcriptional changes) in 


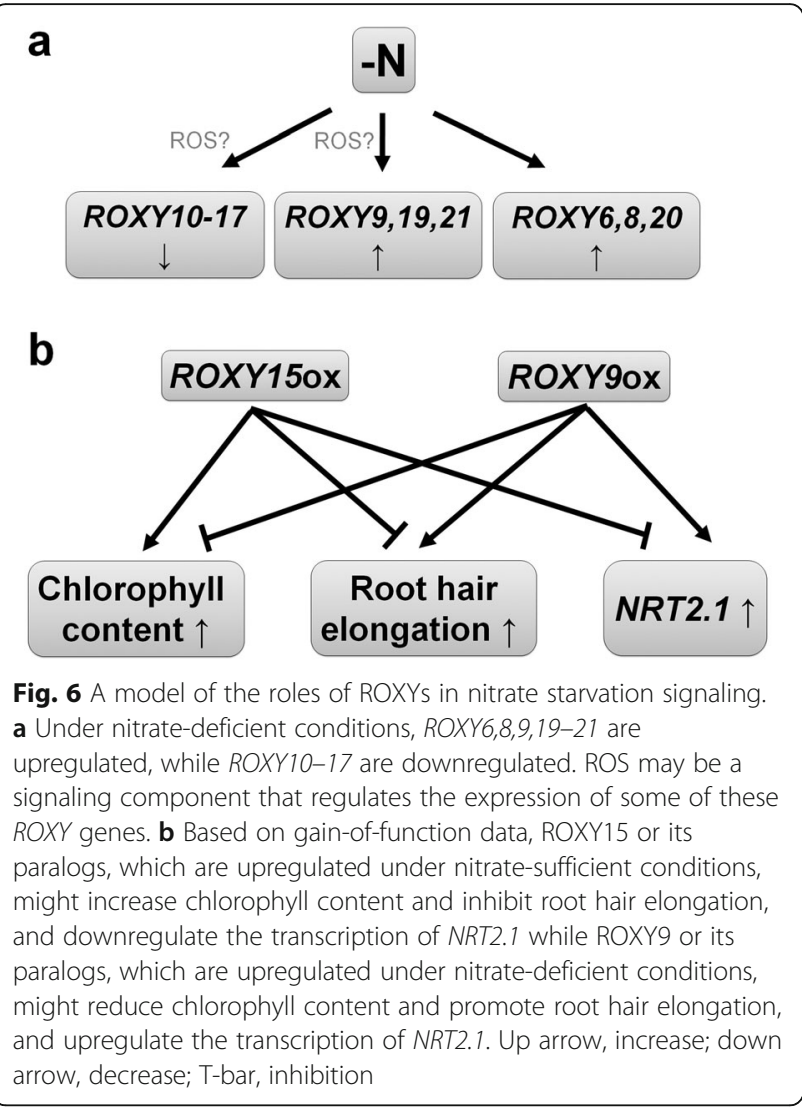

nitrate deprivation signaling pathways. A major question still to be resolved is what the targets of ROXYs are and how ROXYs regulate their downstream targets in nitrate deprivation signal transduction pathway.

\section{Methods}

\section{Plant materials and growth conditions}

All Arabidopsis thaliana wild-type and transgenic lines were Columbia-0 ecotype. Seeds were sterilized in $70 \%$ $(v / v)$ ethanol and $0.05 \%(\mathrm{v} / \mathrm{v})$ Triton X-100 and then planted on $10 \mathrm{~cm}$-diameter sterile plates containing complete nutrient medium $[1.75 \mathrm{mM} \mathrm{KCl,} 2 \mathrm{mM}$ $\mathrm{Ca}\left(\mathrm{NO}_{3}\right)_{2}, 0.5 \mathrm{mM}$ phosphoric acid, $0.75 \mathrm{mM} \mathrm{MgSO}_{4}$, $50 \mu \mathrm{M} \mathrm{H} \mathrm{H}_{3} \mathrm{BO}_{3}, 10 \mu \mathrm{M} \mathrm{MnCl}, 2 \mu \mathrm{M} \mathrm{ZnSO}, 1.5 \mu \mathrm{M}$ $\mathrm{CuSO}_{4}, \quad 0.075 \mu \mathrm{M} \mathrm{NH}_{4} \mathrm{Mo}_{7} \mathrm{O}_{24}, 74 \mu \mathrm{M}$ Fe-EDTA, pH 5.6 with $\mathrm{Ca}(\mathrm{OH})_{2}$ ], 2\% sucrose, and $0.8 \%$ SeaKem agarose (Cambrex). This complete nutrient medium was used throughout the study unless otherwise stated. After stratification of the seeds at $4{ }^{\circ} \mathrm{C}$ for $2 \sim 3$ days, the plates were transferred to the growth chamber at $22{ }^{\circ} \mathrm{C}$ with a $16 \mathrm{~h}$ daylength at $200 \mu \mathrm{mol} \cdot \mathrm{m}^{-2} \mathrm{~s}^{-1}$. Seedlings were grown on vertically oriented plates. Four- to 10-day-old seedlings were used throughout the study. For nitrate-deficient $(-\mathrm{N})$ medium, $2 \mathrm{mM} \mathrm{Ca}\left(\mathrm{NO}_{3}\right)_{2}$ was replaced with $2 \mathrm{mM} \mathrm{CaCl}_{2}$.
Plasmid construction and plant transformation

To generate constructs for the overexpression of ROXY9 and $R O X Y 15$, full-length open reading frames of $R O X Y 9$ and $R O X Y 15$ were amplified by PCR using NEB Phusion polymerase. The PCR products were inserted into pENTR/D-TOPO following the manufacturer's instructions (Invitrogen). The inserts were sequenced to make sure that no changes were introduced by PCR. The resulting entry clones were introduced into the destination plasmid pEARLYGATE100 [86] to yield $p E A R L Y$ GATE100:ROXY9 and pEARLYGATE100:ROXY15, which allows the overexpression of proteins under control of the cauliflower mosaic virus $35 \mathrm{~S}$ promoter. Transgenic Arabidopsis plants carrying pEARLYGATE100:ROXY9 and $p E A R L Y G A T E 100: R O X Y 15$ were generated by Agrobacterium-mediated transformation [87] and $\mathrm{T}_{3}$ homozygous transgenic lines were used in this study.

\section{Quantitative real-time PCR analysis}

For the analysis of NRT2.1 expression levels in the wild type Col-0 seedlings and transgenic seedlings overexpressing ROXY9 or ROXY15, seven-day-old seedlings grown on complete nutrient media were harvested. For the analysis of NRT2.1 expression levels in Col-0 seedlings under nitrate starvation, six-day-old seedlings grown on complete nutrient media were transferred to media with either $4 \mathrm{mM}$ nitrate or no nitrate and further grown for 6,12 , and $24 \mathrm{~h}$. Then, all seedlings were harvested at the end of the light period (zeitgeber time 16). For the analysis of expression levels of ROXY genes in the wild type Col- 0 seedlings with $\mathrm{H}_{2} \mathrm{O}_{2}$, seven-day-old seedlings grown on complete nutrient agar media were floated on the same nutrient liquid media containing $10 \mathrm{mM} \mathrm{H}_{2} \mathrm{O}_{2}$ for 1,3 , and $6 \mathrm{~h}$ and harvested at the same time. Total RNA was isolated by grinding whole seedlings in liquid nitrogen in the presence of Trizol reagent (Invitrogen) according to the manufacturer's instructions. RNA was quantified and treated with RQ RNase-free DNase I (Promega). DNase-treated RNA was tested for genomic DNA contamination, and the quality of total RNA was determined by agarose gel electrophoresis. Two and a half micrograms of DNA-free RNA was then reverse transcribed using the First-Stand Synthesis System (Invitrogen). qRT-PCR analysis was performed using the StepOnePlus Real-Time PCR system (Applied Biosystems) and Platinum SYBR Green qPCR SuperMix-UDG (Invitrogen). The primers used to quantify the gene expression of ROXYs and NRT2.1 were described in Additional file 3. The real-time PCR efficiency in the exponential phase was calculated according to the equation: $E=10^{\wedge}[-1 /$ slope $]$. Statistical differences of the transcript levels of ROXY genes and NRT2.1 between samples were evaluated by a Student's $t$ test using $\Delta \Delta \mathrm{Ct}$ 
values [88]. Three biological replicates were used to generate means and statistical significance.

\section{ROS detection and measurement}

For the localization and measurement of ROS in roots, we employed a membrane permeable fluorescent dye called 5-(and 6-) carboxy-2',7' - difluorodihydrofluorescein diacetate (DFFDA, Invitrogen), an improved photostable version of 2'7'-dichlorodihydrofluorescein diacetate. For the ROS study using wild type Col-0 seedlings, three-day-old seedlings grown on complete nutrient media were floated on liquid media containing either $4 \mathrm{mM}$ nitrate or no nitrate. After $23 \mathrm{~h}$ and $40 \mathrm{~min}$, roots were further incubated with $20 \mu \mathrm{M}$ DFFDA for $20 \mathrm{~min}$. After a brief wash with the medium that did not contain DFFDA, the roots were observed using fluorescence microscopy. All fluorescence images were captured and stored in grayscale using a Nikon SMZ1500 microscope (Nikon,Tokyo, Japan) and a Q-Imaging Retiga cooled 12-bit camera (Burnaby, Canada) with 460-500 nm bandpass excitation and $510-560 \mathrm{~nm}$ bandpass emission. ROS fluorescence in the root hair elongation zone $(\sim$ $0.5 \mathrm{~mm}$ ) was quantified and converted into pseudo-color images by the NIH ImageJ software program (available at rsb.info.nih.gov/ij/). Background noise was subtracted from the fluorescence intensity value for quantification. The same microscopic parameters (i.e., UV exposure time, gain, contrast, etc.) were used to compare ROS signal intensity within specific experiments.

\section{Chlorophyll content measurement}

For the measurement of total chlorophyll content of $R O X Y$ transgenic plants, wild type Col-0 plants and two independent transgenic plants overexpressing $R O X Y 9$ or ROXY15 were grown in Fafard $4 \mathrm{M}$ soil mix in a growth chamber at $22{ }^{\circ} \mathrm{C}$ with a $16 \mathrm{~h}$ daylength at $200 \mu \mathrm{mol} \cdot \mathrm{m}^{-}$ ${ }^{2} \mathrm{~s}^{-1}$ for 3 weeks. Photographs and chlorophyll content measurements of the plants mentioned above were taken. Chlorophyll contents were measured by bulking 2 fully expanded leaves at the same developmental stage from each of ten plants $(n=10)$. For the measurement of total chlorophyll content of plants deprived of nitrate, ten-day-old seedlings grown on complete nutrient media were transferred to media containing either $4 \mathrm{mM} \mathrm{ni}$ trate or no nitrate. The shoots were harvested 4 days after the transfer. Total chlorophyll content were measured by bulking 5 shoots per replicate and 5 replicates were used. Chlorophyll was extracted and assayed according to the procedure of Hiscox and Israelstam (1979). Statistical significance was evaluated with a Student's $t$ test. At least two independent experiments were performed, and similar results were obtained.

\section{Root hair length measurement}

Root hair length was measured using Col- 0 wild-type plants and two independent transgenic plants overexpressing ROXY9 or ROXY15. Photographs of 4-day-old roots were taken using a Nikon SMZ1500 microscope and a Q-Imaging Retiga cooled 12-bit camera. For each root, the length of the root hairs, in a $2 \mathrm{~mm}$ region starting $0.5 \mathrm{~mm}$ above the root hair differentiation zone, was measured ( $n=15$ roots hairs), avoiding root hairs that were growing into the medium, by using NIH ImageJ software program. Ten plants per genotype were used for root hair length measurements $(n=10)$. For the root hair length measurement of plants deprived of nitrate, three-day-old seedlings were transferred to media containing either $4 \mathrm{mM}$ nitrate or no nitrate. Then, root hair length was measured $24 \mathrm{~h}$ after the transfer. At least two independent experiments were performed, and similar results were obtained.

\section{Additional files} Additional file 1: Figure S1. Expression levels of ROXY9 and ROXY15 in
transgenic overexpressor lines. (DOCX $118 \mathrm{~kb})$

Additional file 2: Figure S2. Expression levels of ROXY18, ROXY7, and ROXY16 under low nutrients and $\mathrm{H}_{2} \mathrm{O}_{2}$ treatment. (DOCX $218 \mathrm{~kb}$ )

Additional file 3: Table S1. List of primers used in this research. (DOCX $28 \mathrm{~kb})$

\section{Abbreviations}

DFFDA: 5-(and 6-) carboxy-2',7'-difluorodihydrofluorescein diacetate; GRX: Glutaredoxin; NRT2.1: Nitrate transporter2.1; qRT-PCR: Quantitative reverse-transcription PCR; RHDZ: Root hair differentiation zone; ROS: Reactive oxygen species; ROXY: CC-type glutaredoxin; WT: Wild type

\section{Acknowledgments}

We thank Barbara Kunkel, Douglas Chalker, Joseph Jez, Mark Running, and Robert Kranz for critical comments on the manuscript.

\section{Funding}

This work was financially supported by a grant to JHA from the National Research Foundation of Korea (NRF) funded by the Korean government (NRF- 2017R1A2B3009624). The funding body had no role in the design of the study; collection, analysis, and interpretation of data; or in writing the manuscript.

\section{Availability of data and materials}

All supporting data can be found within the manuscript and its additional file. The datasets used and/or analysed during the current study are available from the corresponding author on reasonable request.

\section{Authors' contributions}

JYJ and DPS conceived and designed the experiments. JYJ performed the experiments and analyzed the data. JYJ, JHA and DPS wrote the manuscript. All authors read and approved the final manuscript.

Ethics approval and consent to participate

The transgenic plants used in this study were generated from Col-0 seeds, which were obtained from Arabidopsis Biological Resource Center. The work carried out complies with institutional, national, and international guidelines.

Consent for publication

Not applicable. 


\section{Competing interests}

The authors declare that the research was conducted in the absence of any commercial or financial relationships that could be construed as a potential conflict of interest.

\section{Publisher's note}

Springer Nature remains neutral with regard to jurisdictional claims in published maps and institutional affiliations.

\section{Received: 6 July 2018 Accepted: 30 October 2018}

\section{Published online: 13 November 2018}

\section{References}

1. Crawford NM, Forde BG. Molecular and developmental biology of inorganic nitrogen nutrition. Arabidopsis Book. 2002;1:e0011.

2. Hachiya T, Sakakibara H. Interactions between nitrate and ammonium in their uptake, allocation, assimilation, and signaling in plants. J Exp Bot. 2016. https://doi.org/10.1093/jxb/erw1449.

3. Masclaux-Daubresse C, Daniel-Vedele F, Dechorgnat J, Chardon F, Gaufichon L, Suzuki A. Nitrogen uptake, assimilation and remobilization in plants: challenges for sustainable and productive agriculture. Ann Bot. 2010;105(7):1141-57.

4. Krouk G, Crawford NM, Coruzzi GM, Tsay YF. Nitrate signaling: adaptation to fluctuating environments. Curr Opin Plant Biol. 2010;13(3):266-73.

5. Miller AJ, Fan X, Orsel M, Smith SJ, Wells DM. Nitrate transport and signalling. J Exp Bot. 2007;58(9):2297-306.

6. Miller AJ, Cramer MD. Root nitrogen acquisition and assimilation. Plant Soil. 2004;274:1-36.

7. Ho CH, Tsay YF. Nitrate, ammonium, and potassium sensing and signaling. Curr Opin Plant Biol. 2010;13(5):604-10.

8. Schachtman DP, Shin R. Nutrient Sensing and Signaling: NPKS. Annu Rev Plant Biol. 2007;58:47-69.

9. Krapp A, David LC, Chardin C, Girin T, Marmagne A, Leprince AS, Chaillou S, Ferrario-Mery S, Meyer C, Daniel-Vedele F. Nitrate transport and signalling in Arabidopsis. J Exp Bot. 2014;65(3):789-98.

10. Vidal EA, Alvarez JM, Moyano TC, Gutierrez RA. Transcriptional networks in the nitrate response of Arabidopsis thaliana. Curr Opin Plant Biol. 2015;27:125-32

11. O'Brien JA, Vega A, Bouguyon E, Krouk G, Gojon A, Coruzzi G, Gutierrez RA. Nitrate transport, sensing, and responses in plants. Mol Plant. 2016; 9(6):837-56.

12. Kiba T, Krapp A. Plant nitrogen acquisition under low availability: regulation of uptake and root architecture. Plant Cell Physiol. 2016;57(4):707-14.

13. Lezhneva L, Kiba T, Feria-Bourrellier AB, Lafouge F, Boutet-Mercey S, Zoufan P, Sakakibara H, Daniel-Vedele F, Krapp A. The Arabidopsis nitrate transporter NRT2.5 plays a role in nitrate acquisition and remobilization in nitrogen-starved plants. Plant J. 2014;80(2):230-41.

14. Rubin G, Tohge T, Matsuda F, Saito K, Scheible WR. Members of the LBD family of transcription factors repress anthocyanin synthesis and affect additional nitrogen responses in Arabidopsis. Plant Cell. 2009; 21(11):3567-84

15. Castaings L, Camargo A, Pocholle D, Gaudon V, Texier Y, Boutet-Mercey S, Taconnat L, Renou JP, Daniel-Vedele F, Fernandez E, et al. The nodule inception-like protein 7 modulates nitrate sensing and metabolism in Arabidopsis. Plant J. 2009;57(3):426-35.

16. Tabata R, Sumida K, Yoshii T, Ohyama K, Shinohara H, Matsubayashi Y. Perception of root-derived peptides by shoot LRR-RKs mediates systemic Ndemand signaling. Science. 2014;346(6207):343-6.

17. Araya T, Miyamoto M, Wibowo J, Suzuki A, Kojima S, Tsuchiya YN, Sawa S, Fukuda H, von Wiren N, Takahashi H. CLE-CLAVATA1 peptide-receptor signaling module regulates the expansion of plant root systems in a nitrogen-dependent manner. Proc Natl Acad Sci U S A. 2014;111(5):2029-34.

18. Zhao M, Ding H, Zhu JK, Zhang F, Li WX. Involvement of miR169 in the nitrogen-starvation responses in Arabidopsis. New Phytol. 2011;190(4): 906-15.

19. Terasaka K, Blakeslee JJ, Titapiwatanakun B, Peer WA, Bandyopadhyay A, Makam SN, Lee OR, Richards EL, Murphy AS, Sato F, et al. PGP4, an ATP binding cassette P-glycoprotein, catalyzes auxin transport in Arabidopsis thaliana roots. Plant Cell. 2005;17(11):2922-39.

20. Ruffel S, Krouk G, Ristova D, Shasha D, Birnbaum KD, Coruzzi GM. Nitrogen economics of root foraging: transitive closure of the nitrate-cytokinin relay and distinct systemic signaling for $\mathrm{N}$ supply vs. demand. Proc Natl Acad Sci U S A. 2011;108(45):18524-9.

21. Ma Q, Tang RJ, Zheng XJ, Wang SM, Luan S. The calcium sensor CBL7 modulates plant responses to low nitrate in Arabidopsis. Biochem Biophys Res Commun. 2015;468(1-2):59-65.

22. Shin R, Berg RH, Schachtman DP. Reactive oxygen species and root hairs in Arabidopsis root response to nitrogen, phosphorus and potassium deficiency. Plant Cell Physiol. 2005;46(8):1350-7.

23. Kong L, Wang F, Si J, Feng B, Zhang B, Li S, Wang Z. Increasing in ROS levels and callose deposition in peduncle vascular bundles of wheat (Triticum aestivum L.) grown under nitrogen deficiency. J Plant Interact. 2013;8(2):109-16.

24. Jung JY, Shin R, Schachtman DP. Ethylene mediates response and tolerance to potassium deprivation in Arabidopsis. Plant Cell. 2009;21(2):607-21.

25. Muller J, Toev T, Heisters M, Teller J, Moore KL, Hause G, Dinesh DC, Burstenbinder K, Abel S. Iron-dependent callose deposition adjusts root meristem maintenance to phosphate availability. Dev Cell. 2015;33(2): 216-30

26. Camacho-Cristobal JJ, Martin-Rejano EM, Herrera-Rodriguez MB, NavarroGochicoa MT, Rexach J, Gonzalez-Fontes A. Boron deficiency inhibits root cell elongation via an ethylene/auxin/ROS-dependent pathway in Arabidopsis seedlings. J Exp Bot. 2015;66(13):3831-40.

27. Shin R, Schachtman DP. Hydrogen peroxide mediates plant root cell response to nutrient deprivation. Proc Natl Acad Sci U S A. 2004;101(23): 8827-32.

28. Foreman J, Demidchik V, Bothwell JH, Mylona P, Miedema H, Torres MA Linstead P, Costa S, Brownlee C, Jones JD, et al. Reactive oxygen species produced by NADPH oxidase regulate plant cell growth. Nature. 2003; 422(6930):442-6.

29. Meyer Y, Buchanan BB, Vignols F, Reichheld JP. Thioredoxins and glutaredoxins: unifying elements in redox biology. Annu Rev Genet. 2009:43:335-67.

30. Rouhier N. Plant glutaredoxins: pivotal players in redox biology and ironSulphur Centre assembly. New Phytol. 2010;186(2):365-72.

31. Rouhier N, Couturier J, Jacquot JP. Genome-wide analysis of plant glutaredoxin systems. J Exp Bot. 2006;57(8):1685-96.

32. Rouhier N, Gelhaye E, Jacquot JP. Plant glutaredoxins: still mysterious reducing systems. Cell Mol Life Sci. 2004:61(11):1266-77.

33. Rouhier N, Lemaire SD, Jacquot JP. The role of glutathione in photosynthetic organisms: emerging functions for glutaredoxins and glutathionylation. Annu Rev Plant Biol. 2008:59:143-66.

34. Gutsche N, Thurow C, Zachgo S, Gatz C. Plant-specific CC-type glutaredoxins: functions in developmental processes and stress responses. Biol Chem. 2015;396(5):495-509.

35. Meyer Y, Belin C, Delorme-Hinoux V, Reichheld JP, Riondet C. Thioredoxin and glutaredoxin systems in plants: molecular mechanisms, crosstalks, and functional significance. Antioxid Redox Signal. 2012:17(8):1124-60.

36. Delorme-Hinoux V, Bangash SA, Meyer AJ, Reichheld JP. Nuclear thiol redox systems in plants. Plant Sci. 2016;243:84-95.

37. Ziemann M, Bhave M, Zachgo S. Origin and diversification of land plant CCtype glutaredoxins. Genome Biol Evol. 2009;1:265-77.

38. Lemaire SD. The glutaredoxin family in oxygenic photosynthetic organisms. Photosynth Res. 2004:79(3):305-18.

39. Xing S, Lauri A, Zachgo S. Redox regulation and flower development: a novel function for glutaredoxins. Plant Biol (Stuttg). 2006:8(5):547-55.

40. Hu Y, Wu Q, Sprague SA, Park J, Oh M, Rajashekar CB, Koiwa H, Nakata PA,

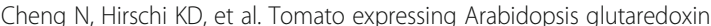
gene AtGRXS17 confers tolerance to chilling stress via modulating cold responsive components. Hortic Res. 2015;2:15051.

41. Wu Q, Lin J, Liu JZ, Wang X, Lim W, Oh M, Park J, Rajashekar CB, Whitham $\mathrm{SA}$, Cheng $\mathrm{NH}$, et al. Ectopic expression of Arabidopsis glutaredoxin AtGRXS17 enhances thermotolerance in tomato. Plant Biotechnol J. 2012; 10(8):945-55.

42. Li S. Redox modulation matters: emerging functions for Glutaredoxins in plant development and stress responses. Plants (Basel). 2014;3(4):559-82.

43. Cheng NH, Liu JZ, Brock A, Nelson RS, Hirschi KD. AtGRXcp, an Arabidopsis chloroplastic glutaredoxin, is critical for protection against protein oxidative damage. J Biol Chem. 2006;281(36):26280-8.

44. Cheng NH. AtGRX4, an Arabidopsis chloroplastic monothiol glutaredoxin, is able to suppress yeast grx 5 mutant phenotypes and respond to oxidative stress. FEBS Lett. 2008;582(6):848-54. 
45. Guo Y, Huang C, Xie Y, Song F, Zhou X. A tomato glutaredoxin gene SIGRX1 regulates plant responses to oxidative, drought and salt stresses. Planta. 2010;232(6):1499-509.

46. Knuesting J, Riondet C, Maria C, Kruse I, Becuwe N, Konig N, Berndt C, Tourrette S, Guilleminot-Montoya J, Herrero E, et al. Arabidopsis glutaredoxin S17 and its partner, the nuclear factor $Y$ subunit $\mathrm{C11/negative}$ cofactor 2alpha, contribute to maintenance of the shoot apical meristem under long-day photoperiod. Plant Physiol. 2015;167(4):1643-58.

47. Laporte D, Olate E, Salinas P, Salazar M, Jordana X, Holuigue L. Glutaredoxin GRXS13 plays a key role in protection against photooxidative stress in Arabidopsis. J Exp Bot. 2012;63(1):503-15.

48. Moseler A, Aller I, Wagner S, Nietzel T, Przybyla-Toscano J, Muhlenhoff U, Lill $\mathrm{R}$, Berndt C, Rouhier N, Schwarzlander M, et al. The mitochondrial monothiol glutaredoxin S15 is essential for iron-sulfur protein maturation in Arabidopsis thaliana. Proc Natl Acad Sci U S A. 2015;112(44):13735-40.

49. Stroher E, Grassl J, Carrie C, Fenske R, Whelan J, Millar AH. Glutaredoxin S15 is involved in Fe-S cluster transfer in mitochondria influencing lipoic aciddependent enzymes, plant growth, and Arsenic Tolerance in Arabidopsis. Plant Physiol. 2016;170(3):1284-99.

50. Verma PK, Verma S, Pande V, Mallick S, Deo Tripathi R, Dhankher OP, Chakrabarty D. Overexpression of Rice Glutaredoxin OsGrx_C7 and OsGrx_C2.1 reduces intracellular arsenic accumulation and increases tolerance in Arabidopsis thaliana. Front Plant Sci. 2016;7:740.

51. Wu Q, Hu Y, Sprague SA, Kakeshpour T, Park J, Nakata PA, Cheng N, Hirschi KD, White FF, Park S. Expression of a monothiol glutaredoxin, AtGRXS17, in tomato (Solanum lycopersicum) enhances drought tolerance. Biochem Biophys Res Commun. 2017:491(4):1034-9.

52. Yu H, Yang J, Shi Y, Donelson J, Thompson SM, Sprague S, Roshan T, Wang DL, Liu J, Park S, et al. Arabidopsis Glutaredoxin S17 contributes to vegetative growth, mineral accumulation, and redox balance during Iron deficiency. Front Plant Sci. 2017:8:1045.

53. Sharma R, Priya $P$, Jain M. Modified expression of an auxin-responsive rice CC-type glutaredoxin gene affects multiple abiotic stress responses. Planta. 2013;238(5):871-84.

54. Xing S, Zachgo S. ROXY1 and ROXY2, two Arabidopsis glutaredoxin genes, are required for anther development. Plant J. 2008;53(5):790-801.

55. Xing S, Rosso MG, Zachgo S. ROXY1, a member of the plant glutaredoxin family, is required for petal development in Arabidopsis thaliana. Development. 2005;132(7):1555-65.

56. El-Kereamy A, Bi YM, Mahmood K, Ranathunge K, Yaish MW, Nambara E, Rothstein SJ. Overexpression of the CC-type glutaredoxin, OsGRX6 affects hormone and nitrogen status in rice plants. Front Plant Sci. 2015;6:934

57. Patterson K, Walters LA, Cooper AM, Olvera JG, Rosas MA, Rasmusson AG, Escobar MA. Nitrate-regulated Glutaredoxins control Arabidopsis primary root growth. Plant Physiol. 2016;170(2):989-99.

58. Wang Z, Xing S, Birkenbihl RP, Zachgo S. Conserved functions of Arabidopsis and rice CC-type glutaredoxins in flower development and pathogen response. Mol Plant. 2009;2(2):323-35.

59. Yang F, Bui HT, Pautler M, Llaca $V$, Johnston $R$, Lee $B H$, Kolbe A, Sakai $H$, Jackson D. A maize glutaredoxin gene, abphyl2, regulates shoot meristem size and phyllotaxy. Plant Cell. 2015;27(1):121-31.

60. Wu QY, Yang J, Cheng NH, Hirschi KD, White FF, Park S. Glutaredoxins in plant development, abiotic stress response, and iron homeostasis: from model organisms to crops. Environ Exp Bot. 2017;139:91-8.

61. Li S, Lauri A, Ziemann M, Busch A, Bhave M, Zachgo S. Nuclear activity of ROXY1, a glutaredoxin interacting with TGA factors, is required for petal development in Arabidopsis thaliana. Plant Cell. 2009;21(2):429-41.

62. Murmu J, Bush MJ, DeLong C, Li S, Xu M, Khan M, Malcolmson C, Fobert PR, Zachgo S, Hepworth SR. Arabidopsis basic leucine-zipper transcription factors TGA9 and TGA10 interact with floral glutaredoxins ROXY1 and ROXY2 and are redundantly required for anther development. Plant Physiol. 2010;154(3):1492-504

63. Li S, Gutsche N, Zachgo S. The ROXY1 C-terminal $L^{* *} L L$ motif is essential for the interaction with TGA transcription factors. Plant Physiol. 2011;157(4):2056-68.

64. Hou X, Hu WW, Shen L, Lee LY, Tao Z, Han JH, Yu H. Global identification of DELLA target genes during Arabidopsis flower development. Plant Physiol. 2008;147(3):1126-42.

65. Huang LJ, Li N, Thurow C, Wirtz M, Hell R, Gatz C. Ectopically expressed glutaredoxin ROXY19 negatively regulates the detoxification pathway in Arabidopsis thaliana. BMC Plant Biol. 2016;16(1):200.
66. Ndamukong I, Abdallat AA, Thurow C, Fode B, Zander M, Weigel R, Gatz C. SA-inducible Arabidopsis glutaredoxin interacts with TGA factors and suppresses JA-responsive PDF1.2 transcription. Plant J. 2007:50(1):128-39.

67. Zander M, Chen S, Imkampe J, Thurow C, Gatz C. Repression of the Arabidopsis thaliana jasmonic acid/ethylene-induced defense pathway by TGA-interacting glutaredoxins depends on their C-terminal ALWL motif. Mol Plant. 2012;5(4):831-40.

68. Uhrig JF, Huang LJ, Barghahn S, Willmer M, Thurow C, Gatz C. CC-type glutaredoxins recruit the transcriptional co-repressor TOPLESS to TGAdependent target promoters in Arabidopsis thaliana. Biochim Biophys Acta. 2016;1860(2):218-26.

69. Walters LA, Escobar MA. The AtGRXS3/4/5/7/8 glutaredoxin gene cluster on Arabidopsis thaliana chromosome 4 is coordinately regulated by nitrate and appears to control primary root growth. Plant Signal Behav. 2016;11(4):e1171450.

70. Belin C, Bashandy T, Cela J, Delorme-Hinoux V, Riondet C, Reichheld JP. A comprehensive study of thiol reduction gene expression under stress conditions in Arabidopsis thaliana. Plant Cell Environ. 2015; 38(2):299-314.

71. Scheible WR, Morcuende R, Czechowski T, Fritz C, Osuna D, PalaciosRojas N, Schindelasch D, Thimm O, Udvardi MK, Stitt M. Genome-wide reprogramming of primary and secondary metabolism, protein synthesis, cellular growth processes, and the regulatory infrastructure of Arabidopsis in response to nitrogen. Plant Physiol. 2004;136(1): 2483-99.

72. Ho CH, Lin SH, Hu HC, Tsay YF. CHL1 functions as a nitrate sensor in plants. Cell. 2009;138(6):1184-94.

73. Wang $R$, Xing $X$, Wang $Y$, Tran A, Crawford NM. A genetic screen for nitrate regulatory mutants captures the nitrate transporter gene NRT1.1. Plant Physiol. 2009;151(1):472-8.

74. Ciompi S, Gentili E, Guidi L, Soldatini GF. The effect of nitrogen deficiency on leaf gas exchange and chlorophyll fluorescence parameters in sunflower. Plant Sci. 1996:118(2):177-84.

75. Khamis S, Lamaze T, Lemoine $Y$, Foyer C. Adaptation of the photosynthetic apparatus in maize leaves as a result of nitrogen limitation : relationships between Electron transport and carbon assimilation. Plant Physiol. 1990;94(3):1436-43.

76. Cartelata A, Cerovic ZG, Goulasa aY, Meyera S, Lelargeb C, Prioulb J-L, Barbottinc A, Jeuffroyc M-H, Gated P, Agatie G, et al. Optically assessed contents of leaf polyphenolics and chlorophyll as indicators of nitrogen deficiency in wheat (Triticum aestivum L.). Field Crop Res. 2005:91(1):35-49.

77. Engineer CB, Kranz RG. Reciprocal leaf and root expression of AtAmt1.1 and root architectural changes in response to nitrogen starvation. Plant Physiol. 2007;143(1):236-50.

78. Zhu C, Yang N, Guo Z, Qian M, Gan L. An ethylene and ROSdependent pathway is involved in low ammonium-induced root hair elongation in Arabidopsis seedlings. Plant Physiol Biochem. 2016;105: 37-44.

79. Lejay L, Tillard P, Lepetit M, Olive F, Filleur S, Daniel-Vedele F, Gojon A. Molecular and functional regulation of two NO3- uptake systems by N- and C-status of Arabidopsis plants. Plant J. 1999;18(5):509-19.

80. Munos S, Cazettes C, Fizames C, Gaymard F, Tillard P, Lepetit M, Lejay L, Gojon A. Transcript profiling in the chl1-5 mutant of Arabidopsis reveals a role of the nitrate transporter NRT1.1 in the regulation of another nitrate transporter, NRT2.1. Plant Cell. 2004;16(9):2433-47.

81. Kiba T, Feria-Bourrellier AB, Lafouge F, Lezhneva L, Boutet-Mercey $S$, Orsel M, Brehaut V, Miller A, Daniel-Vedele F, Sakakibara $H$, et al. The Arabidopsis nitrate transporter NRT2.4 plays a double role in roots and shoots of nitrogen-starved plants. Plant Cell. 2012;24(1):245-58.

82. He H, Liang G, Li Y, Wang F, Yu D. Two young MicroRNAs originating from target duplication mediate nitrogen starvation adaptation via regulation of glucosinolate synthesis in Arabidopsis thaliana. Plant Physiol. 2014;164(2):853-65.

83. Rouhier N, Villarejo A, Srivastava M, Gelhaye E, Keech O, Droux M, Finkemeier I, Samuelsson G, Dietz KJ, Jacquot JP, et al. Identification of plant glutaredoxin targets. Antioxid Redox Signal. 2005;7(7-8): 919-29.

84. Pineda-Molina E, Klatt P, Vazquez J, Marina A, Garcia de Lacoba M, Perez-Sala D, Lamas S. Glutathionylation of the p50 subunit of NF- 
kappaB: a mechanism for redox-induced inhibition of DNA binding. Biochemistry. 2001;40(47):14134-42.

85. Alvarez JM, Riveras E, Vidal EA, Gras DE, Contreras-Lopez O, Tamayo KP, Aceituno F, Gomez I, Ruffel S, Lejay L, et al. Systems approach identifies TGA1 and TGA4 transcription factors as important regulatory components of the nitrate response of Arabidopsis thaliana roots. Plant J. 2014;80(1):1-13.

86. Earley KW, Haag JR, Pontes O, Opper K, Juehne T, Song K, Pikaard CS. Gateway-compatible vectors for plant functional genomics and proteomics. Plant J. 2006;45(4):616-29.

87. Clough SJ, Bent AF. Floral dip: a simplified method for agrobacteriummediated transformation of Arabidopsis thaliana. Plant J. 1998;16(6):735-43.

88. Yuan JS, Reed A, Chen F, Stewart CN Jr. Statistical analysis of real-time PCR data. BMC Bioinformatics. 2006;7:85.

Ready to submit your research? Choose BMC and benefit from:

- fast, convenient online submission

- thorough peer review by experienced researchers in your field

- rapid publication on acceptance

- support for research data, including large and complex data types

- gold Open Access which fosters wider collaboration and increased citations

- maximum visibility for your research: over $100 \mathrm{M}$ website views per year

At BMC, research is always in progress.

Learn more biomedcentral.com/submissions 